\title{
Quality of care for chalazion surgery between nursing and medical staff
}

\author{
Abstract \\ Aim: To prospectively study the quality of care for chalazion surgery between nursing and \\ medical staff. \\ Methods: Patients who underwent chalazion removal surgery in the minor operations \\ department at Western Eye Hospital between January 2010 to March 2010 by nursing staff \\ and November 2010 to March 2011 by medical staff. \\ Results: The service provided for chalazion removal was well received. Overall there \\ was no difference between quality of care between the nursing and medical staff. There \\ were some points highlighted by patients regarding the general practice referral and pre \\ appointment information.
}

Conclusion: Nurse led chalazion removal has shown to a safe effective solution to future economic rationalisation for elective minor procedures. A high level of quality of care for the service has been shown.
Volume 9 Issue 5 - 2019

\author{
Ahmad Aziz,' Rushmia Karim, ${ }^{2}$ Thomas \\ Francis Lynch, ${ }^{3}$ Vickie Lee, ' Ahmed \\ Alnahrawy, Rajni Jain ${ }^{2}$ \\ 'Western Eye Hospital, Imperial College Healthcare NHS Trust, \\ UK \\ ${ }^{2}$ Royal Berkshire Hospital, UK \\ ${ }^{3}$ Charing Cross Hospital, Imperial College Healthcare NHS \\ Trust, UK
}

Correspondence: Ahmad Aziz, Western Eye Hospital, Imperial

College Healthcare NHS Trust, 153-173 Marylebone Road,

London NWI 5QH, UK, Tel 07545884204,

Email ahmad.aziz@nhs.net

Received: September 24, 2019 | Published: October 21, 2019

\section{Introduction}

A chalazion is a localised cystic swelling that forms on the upper or lower eyelids. They are formed from the blockage of the Meibomian glands and are also called Meibomian cysts. Few cause complications of cellulitis and conjunctivitis. The majority are unsightly and uncomfortable. It has been suggested that approximately $25-50 \%$ resolve with lid hygiene and hot compressors. ${ }^{1,2}$ The most recent prospective study shows a $46 \%$ resolution rate within 3 weeks of hot wet compressors. ${ }^{3}$ Further intervention includes injection of triamcinolone or surgical incision and curettage. Resolution rates in the triamcinolone acetonide injection and surgical treatment groups in the most recent study were found to be similar at $84 \%$ and 87 $\% .^{3}$ However long tern efficacy of triamcinolone was questioned in a study with patients requiring further injections for resolution. ${ }^{4}$ There have been a few cases of depigmentation with triamcinolone injections with certain administrative routes. ${ }^{5}$ Although pain scores maybe higher in surgical intervention there is good resolution rate. High success rates have been consistent in the medical literature. ${ }^{3,6-8}$ This mode of treatment was chosen for our study comparing surgeries of chalazia under nursing and medical staff. The quality of care received by patients was the focus of the study with aims to expand nursing led minor operations. Given the climate of health economics and rationalisation utilising the existing skilled nursing staff seems like a sustainable solution to diminishing resources paralleled with increased demand for quality service.

\section{Aim}

To prospectively study the quality of care of surgical treatment of chalazia provided by nursing and medical staff at a tertiary referral centre.

\section{Methods}

Patients undertaking chalazion removal with incision and curettage were asked to fill out a voluntary questionnaire regarding the quality of care they received during their operation including pain scores, overall service, and adequate explanation of procedure and answering of questions. Space was given in the survey for feedback and general comments. The questionnaire was given and completed by the patient before leaving the department following procedure and submitted to the receptionist or department staff. Patient inclusion and exclusion criteria are outlined in Table 1. All surgeries were performed in the minor operations room within the casualty department. Surgeries were performed by either Ophthalmic Nurse Practitioners or ophthalmology SHO. Both health professionals performed Incision and Curettage with a chalazion clamp. Local anaesthetic injected was standardized and all patients were given premixed Xylocaine with 1:200000 adrenaline. 50 surveys were completed for the nursing led surgery between January to March 2010. 44 surveys were completed for SHO led surgery between November 2010 and March 2011. Questionnaires were collected by one investigator not involved in the surgery. All patients had the same post operative care. Patients were given Chloramphenicol ointment for one week to treated eye and asked to undertake hot compressors and lid hygiene post operatively. A pamphlet was given on chalazion treatment and post operative care. Lid hygiene and hot compressors education was given to every patient. 41 patients were surveyed and asked who they would prefer for the management of their chalazion. $5 \%$ choose a nurse, $46 \%$ a doctor and $49 \%$ choose either.

Table I Criteria for the study

\begin{tabular}{ll}
\hline $\begin{array}{l}\text { Inclusion } \\
\text { Criteria }\end{array}$ & Age 16 years and above \\
\hline $\begin{array}{l}\text { Exclusion } \\
\text { criteria }\end{array}$ & Known malignant lid lesion \\
& $\begin{array}{l}\text { Chalazion near punctum and canaliculi needing main } \\
\text { theatre } \\
\end{array}$ \\
& $\begin{array}{l}\text { Chalazion removed by consultant ophthalmologist } \\
\text { Multiple Chalazia }\end{array}$ \\
\hline
\end{tabular}




\section{Incision and curettage}

This procedure was performed under sterile conditions with prepping of the face and draping. The surgeon wore theatre scrubs and sterile gloves. Patients were laid on an operating trolley. Patients received $0.5 \%$ proxymethacaine and/or tetracycline topically to the conjunctiva to both eyes and the facial skin was prepped with betadine or chlorhexidine. Up to $1 \mathrm{ml}$ of premixed Xylocaine with 1:200000 adrenaline was given on insulin syringe and needle (30 gages). The skin was checked for anesthesia. A chalazion clamp was placed over the chalazion. A vertical incision was made follow by curettage of the chalazion to break up any inoculations. The eye lid was palpated to check for further chalazion and effectiveness. The eye was double padded with gelanet for 4 hours.

\section{Results}

Of the 94 patients survey $44 \%$ were female and $56 \%$ were male. The mean age was 45 years. Results of the questionnaire are outlined in Table 2. Patients' comments are presented in Table 3. The service provided for chalazion removal was well received. Overall there was no difference between quality of care between the nursing and medical staff. There were some points highlighted by patients regarding the general practice referral and pre appointment information.

Table 2 Results of the questionnaire

\begin{tabular}{|c|c|c|}
\hline & Nurse & SHO \\
\hline Was the procedure explained & $96 \%$ yes $2 \%$ no need $2 \%$ yes somewhat & $100 \%$ \\
\hline Did the practitioner answer any questions (Yes) & $100 \%$ & $100 \%$ \\
\hline Did you feel comfortable throughout the procedure (Yes) & $100 \%$ & $100 \%$ \\
\hline Did you feel that your pain was adequately controlled (Yes) & $100 \%$ & $100 \%$ \\
\hline Were you satisfied with the service (Yes) & $100 \%$ & $100 \%$ \\
\hline How would you rate the service (Yes) & $100 \%$ & $100 \%$ \\
\hline Would you use this service again (Yes) & $100 \%$ & $100 \%$ \\
\hline
\end{tabular}

Table 3 Patients responses

\begin{abstract}
Comments
I thought my appointment was with a doctor and only to find a nurse. I had her remove my cyst because it was bothering me otherwise would have waited for a doctor appointment.

I was too nervous but the nurse was very good she even put music so it would distract me from surgery.

Had the surgery before so I new what to expect although the GP cannot account for the information about the surgery as he was clueless

Great service by the NHS

GP told me that I would have the lump removed in the first appointment which did not happen I had to wait a further appointment. Fortunately I asked to come back earlier. Overall the treatment that I received was outstanding but would have benefited from clearer information from GP about the process. GP would benefit from more guidance on eye conditions. I believe that due to inconsistent information it had an impact on the condition I was upon arrival on the day of my procedure.
\end{abstract}

I only found out what would happen in surgery when I came to casualty.

Had this type of surgery before and waited about 2 and half months but this time I was seen much quicker

Didn't know that the appointment was for surgery as GP told me that I was only coming for an appointment for the doctor to tell me what it was and what could be done.

\section{Discussion}

The last study looking at outcomes for nursing and medical staff was performed over a decade ago. ${ }^{7}$ Conservative treatment was found to be successful for $29 \%$ of cysts while surgical treatment was successful for $72 \%$. There was no significant difference in treatment outcome between nurse and SHO groups. ${ }^{7}$ Our study showed mirrors results with patients overall rating the service to be good or excellent. Our study concentrates on assessing the quality of care patients received during the whole process. All patients found nurse treatment acceptable with a high level of patient satisfaction, adequate pain control and quality of care. This was similar for the medical staff. Most comments were regards to general practitioner referrals.
Questionnaires were given on the day of surgery to ensure compliance and this may have introduced bias in the results. Staff performing the procedure was aware of the survey which may have bias the high satisfaction scores. Patients may have felt they had to give a higher overall score. Although all patients who had the surgery were given questionnaires they were entirely voluntary. Patients were required to hand the survey to the reception staff or allocated box at reception. It is possible a cohort of patients was missed and did not hand in the questionnaire. The questionnaires collected in a sealed box were only handled by the investigator who did not perform any of the procedures. At presents approximately 7 chalazion surgeries are performed on each minor operations list. Our modest numbers 
reflects list cancellations during leave and the Christmas period. As more nursing staff are trained to perform chalazion surgery cancelled lists may not be an issue with adequate cross cover of medical and nursing staff. Patient also failed to turn up and this may be due to miss information from the general practice referral. This study further reiterates the need to address patient quality of care in an under resourced health system. Nurse led chalazion removal has shown to a safe effective solution to future economic rationalization for elective minor procedures. We have shown a high level of quality of care for the service and scope for future cost effect growth.

\section{Acknowledgments}

None.

\section{Conflicts of interest}

Author declares that there is no conflict of interest.

\section{References}

1. Cottrell DG, Bosanquet RC, Fawcett IM. Chalazions: the frequency of spontaneous resolution. Br Med J (Clin Res Ed). 1983;287(6405):1595.
2. Perry HD, Serniuk RA. Conservative treatment of chalazia. Ophthalmology. 1980;87(3):218-221.

3. Goawalla A, Lee V. A prospective randomized treatment study comparing three treatment options for chalazia: triamcinolone acetonide injections, incision and curettage and treatment with hot compresses. Clin Exp Ophthalmol. 2007;35(8):706-712.

4. Ben Simon GJ, Huang L, Nakra T, et al. Intralesional triamcinolone acetonide injection for primary and recurrent chalazia: is it really effective? Ophthalmology. 2005;112(5):913-917.

5. Cohen BZ, Tripathi RC. Eyelid depigmentation after intralesional injection of a fluorinated corticosteroid for chalazion. Am J Ophthalmol. 1979;88(2):269-270.

6. Prasad S, Gupta AK. Subconjunctival total excision in the treatment of chronic chalazia. Indian J Ophthalmol. 1992;40(4):103-105.

7. Jacobs PM, Thaller VT, Wong D. Intralesional corticosteroid therapy of chalazia: a comparison with incision and curettage. Br J Ophthalmol. 1984;68(11):836-837.

8. Jackson TL, Beun L. A prospective study of cost, patient satisfaction, and outcome of treatment of chalazion by medical and nursing staff. $\mathrm{Br}$ J Ophthalmol. 2000;84(7):782-785. 